\title{
The Effect of Rational and Intuitive Decision-Making Strategies on Interest Appraisals
}

Thomas C. Motl

University of North Dakota, thomas.motl@UND.edu

Thomas S. Krieshok

Karen D. Multon

How does access to this work benefit you? Let us know!

Follow this and additional works at: https://commons.und.edu/ehb-fac

Part of the Psychology Commons

\section{Recommended Citation}

Thomas C. Motl, Thomas S. Krieshok, and Karen D. Multon. "The Effect of Rational and Intuitive DecisionMaking Strategies on Interest Appraisals" (2017). Education, Health \& Behavior Studies Faculty Publications. 1.

https://commons.und.edu/ehb-fac/1

This Article is brought to you for free and open access by the Department of Education, Health \& Behavior Studies at UND Scholarly Commons. It has been accepted for inclusion in Education, Health \& Behavior Studies Faculty Publications by an authorized administrator of UND Scholarly Commons. For more information, please contact und.commons@library.und.edu. 


\title{
The Effect of Rational and Intuitive Decision-Making Strategies on Interest Appraisals
}

Thomas C. Motl, University of North Dakota

Thomas S. Krieshok, University of Kansas

Karen D. Multon, University of Kansas

\begin{abstract}
Career counseling requires clients to make assessments and predictions of their interests, necessitating the use of both rational and intuitive processes. Dual-processing models of human decisionmaking have not been experimentally explored within the context of vocational assessment. One-hundred thirty-six participants chose among eight occupational/educational videos after an unconscious-intuitive, conscious-rational, or decisionas-usual information processing manipulation. Participant interest was assessed before, during, and 2 weeks following the video in order to determine differences across conditions. The results yielded three conclusions. First, the unconscious-intuitive manipulation resulted in interest forecasts that were more predictive of actual interest than did the conscious-rational manipulation or the decision-as-usual conditions. Second, interest levels were recalled more accurately by participants who made choices under unconsciousintuitive conditions than by those in the other two conditions. Finally, a history of occupational engagement was found to be related to decisional quality but only for the control group. These results are discussed in the context of vocational theory.
\end{abstract}

Keywords: decision-making, vocational psychology, vocational interests, interest forecasting, rational, intuitive 
Appropriateness of one's career decisions has been an explicit component of most prominent vocational theories (e.g., Holland, Sorensen, Clack, Nafziger, \& Blum, 1973; Krumboltz, 2009; Parsons, 1909; Super, 1980). Trait-factor matching, the most commonly practiced technique in career counseling, explicitly promotes deliberate inspection of client goals, values, and needs in order to determine the occupation with the greatest personal congruence (Holland et al., 1973; James \& Gilliland, 2003). Vocational psychologists who adopt this paradigm often coach their clients through the deliberation process, in hopes that clients will think more rigorously and systematically about themselves and their situation. This process often invokes the pro and con "balance sheet” method of decision-making (Janis \& Mann, 1977), or a similar way of quantifying, calculating, and comparing internal experiences. When discussing the role of strategic deliberation in career counseling, Krieshok (1998) noted that "all of the available prescriptive models mandate self-knowledge” gained through introspection (p. 215). But the hyperrational and introspective approach promoted by most career counseling practices has been challenged by many current researchers (e.g., Dijksterhuis \& Nordgren, 2006; Wilson, 2002). Reflecting on two decades of research, Klein (2003) observed that the "thorough, systematic, rational, and scientific" model of decision-making is "a myth . . . that simply does not work very well in practice” (p. 20).

The goals of this article are to expand upon vocational theories that offer alternatives to the reductionistic, rational, introspective approach implicit to many of our career assessments; to introduce experimental methods that may be helpful to further explore vocational decisions under controlled conditions; and to describe one experiment that yielded promising results. The pertinent vocational theories (e.g., Krieshok, 2001) incorporate dual-processing models of human cognition in order to integrate the career literature with modern decision-making research. An 
overview of dual-processing models is presented before a discussion of pertinent vocational theories, and a review of experimental designs commonly used to assess similar constructs.

\section{An Introduction to Dual-Processing Theories of Decision-Making}

Dual-processing theories assert that all cognitive work can be divided between two discrete but interacting processes (Evans, 2008). These theories share a core assumption: there are two information-processing systems that fluidly exchange information, share responsibilities, and often have discrepant goals (Evans, 2008; Wilson, 2002). One system has been described as conscious, controlled, rational, explicit, analytic, rule based, and higher order. Miller (1956) famously quantified the capacity of this slow, effortful process as "seven, plus or minus two." The second system has a different set of characteristics: unconscious, automatic, heuristic, intuitive, holistic, associative, and impulsive. This system is generally believed to be limitless and presymbolic, meaning that it is not restricted by capacity or language (Evans, 2008). Dualprocessing theories have been applied to a variety of fields, including economics (heuristics and biases; Kahneman \& Tversky, 1996), psychodynamic theory (cognitive-experiential self-theory; Epstein, 1994), developmental psychology (fuzzy trace theory [FTT]; Reyna \& Brainerd, 1995), and social psychology (unconscious thought theory; Dijksterhuis \& Nordgren, 2006). Crosstheoretical hallmarks of the processes will suffice as monikers: conscious-rational will denote the former and unconscious-intuitive the latter.

The conscious-rational system is limited but has the ability to deal in abstraction. This system is flexible but easily fooled by spurious information or overwhelmed by stimulus-rich environments. Conversely, the unconscious-intuitive system is not limited by capacity or language - it relies on gist, image, and emotion. Research has robustly supported the notion that 
a nonconscious cognitive system exists and that it plays an indispensable role in human decisionmaking and goal setting (e.g., Bargh \& Chartrand, 1999; Kahneman \& Tversky, 1996).

Dual-processing models suggest conscious and nonconscious appraisals of self-related constructs may be divergent or conflicting. For example, Melchior and Cheek (1990) found that though most individuals who were shy during childhood had "grown out of it" during adolescence, their selfnarratives oftentimes did not reflect this change. Greenwald and Farnham (2000) measured implicit and explicit self-esteem and found that the two only weakly correlated with one another and that implicit self-esteem was a better predictor of one's response to failure. Furthermore, individuals can employ new strategies based on information they are unaware they have learned (e.g., Bechara, Damasio, Tranell, \& Damasio, 1997) and enact social repertoires they are unaware they have developed (e.g., Greenwald \& Farnham, 2000). In such cases, an individual's consciously held story about their characteristics and abilities has diverged from unconsciously driven behavior.

Wilson (2002) argues that the two processes can result in separate but stable "personalities," each functioning on its own information and strategies. Big decisions, such as who to marry, where to live, or what job to take, are generally under the purview of the conscious-rational personality. Deliberative, conscious-rational decisions are akin to one's identity, a socially constructed view of what one ought to do, think, and feel based on active selfstories and conscious self-evaluations. Unconscious-intuitive processes, on the other hand, produce one's reactions and feelings based on patterns of experience. This dualistic view has substantial implications for vocational psychology, suggesting that interventions and instruments focusing on explicit notions of self may be misleading (Krieshok, 1998). Wilson summarizes, "When choosing a career, for example, it would be to people's advantage to know whether their 
unconscious personalities were better suited for a life as a lawyer, salesperson, or circus performer” (p. 91).

\section{Dual-Processing Models in Vocational Psychology}

Making a career choice is precisely the type of decision that, according to most dualprocessing models (e.g., Dijksterhuis \& Nordgren, 2006; Epstein, 1994; Wilson, 2002), should place a premium on information generated and employed by the unconscious-intuitive thought apparatus. However, vocational counseling theory, assessment, and practice emphasize conscious, reductionist, and deliberative forecasting. For example, the Strong Interest Inventory (Donnay \& Borgen, 1996) and the Self-Directed Search (Holland, 1978) rely on an introspective, conscious-rational approach to data collection and integration.

Krieshok’s (1998) “anti-introspectivist perspective” (AI) argues that interventions based on introspection are theoretically problematic, and available career counseling techniques are susceptible to cognitive distortions and forecasting errors. AI theories exist on a continuum. Under the strictest AI approach, conscious thoughts, beliefs, and "will” have little or no bearing on actions. Introspective efforts result in nothing more than a plausible account of why one has acted the way one has, based on the most accessible (but not necessarily accurate) selfknowledge. Decisions based on these verbalized narratives are likely to be built on partial—and potentially faulty_-inferences. Career assessments, therefore, may reflect self-narratives that have limited basis in reality or history. From this perspective, the cognitive process underlying introspective tasks is more akin to self-fabrication than to self-exploration. If the strictest AI approach is correct, career counselors would be well advised to avoid interventions that require clients to explicitly introspect, quantify, and rank their preferences. 
Less radical AI approaches view accurate self-reflection as difficult but not impossible to achieve (Krieshok, 1998). This view recalls Freud's famous iceberg metaphor: only a small amount of mental life resides above the waterline of consciousness. The underlying mass is not entirely inaccessible, but its discovery requires exploration and effort. Disciplined inquiry through journaling, guided imagery, and counseling can aid this endeavor. These exercises can yield valuable information regarding personal values and life themes, as long as clients adopt a flexible and open approach to their previously held self-narratives.

AI theory suggests that, based on the dual-processing literature, the optimal strategy for career exploration is to experientially engage in the possible occupations of interest (Krieshok, 2001). Direct experience in the world uses the full depth of information available to the nonconscious system. Reading about the world and introspecting, as suggested by traditional career counseling, activates only the narrow, superficial conscious-rational system. Krieshok, Black, and McKay (2009) formulated the trilateral model of adaptive decision-making, which postulates that both intuitive and rational processes are vital for adaptive career decision-making. Neither process, however, can develop in a vacuum. The researchers termed the meaningful activities that fund both intuitive and rational knowledge bases as "occupational engagement."

Occupational engagement informs the decision-making process via direct experience. The trilateral model of adaptive career decision-making (Krieshok et al., 2009) predicts that activities which promote greater interaction (engagement) with the options of interest will lead to more optimal choices. Behavioral engagement is fundamentally about immersing oneself with the stimuli that accompany the options. The best way to determine how you will feel about a certain job, major, or hobby is to truly "feel” it out, by developing gist-level affective responses to a vast array of contextual cues, job-relevant tasks, and environmental feedback. Consciously 
thinking about potential jobs is more engaging than nothing, but talking to those who have had those jobs is better. Looking up information about a job on the Internet is more engaging than nothing, but shadowing someone with that job for a day is better.

\section{Experimental Methodology for Affective Forecasting}

The trilateral model of adaptive career decision-making contends that occupational engagement will inform both the conscious-rational and unconscious-intuitive systems, improving one's ability to predict the type and intensity of emotions that will arise as they approach certain jobs or tasks. The process of emotional prediction is called affective forecasting (Wilson \& Gilbert, 2005). Though it has yet to be applied to career-related issues, a substantial research base has established experimental research methods that use dual-processing paradigms to explore the conditions that optimize affective forecasts.

Experimental methods can reliably manipulate usage of the unconscious-intuitive and consciousrational systems, effectively putting one or the other in the "driver's seat" during the decisionmaking process. Conscious-rational processes can be accentuated by asking an individual to actively deliberate before making a choice (e.g., Wilson, 2002), or by creating a list of positive and negative attributes based on the tasks or objects they are to decide between (e.g., Dijksterhuis \& van Olden, 2006; Wilson \& Schooler, 1991). Conversely, it is possible to overwhelm the conscious-rational system by forcing participants to engage in an ongoing mental chore (e.g., Bargh \& Chartrand, 1999), by inducing immediate judgments (e.g., Dijksterhuis \& van Olden, 2006), or by measuring implicit associations (e.g., Greenwald, McGhee, \& Schwartz, 1998). Employing different forms of these procedures, both Dijksterhuis and Nordgren (2006)

and Levine, Halberstadt, and Goldstone (1996) have found that judgments and predictions made 
under unconscious-intuitive conditions are more consistent, per test-retest reliability, than those made under rational conditions.

Using these methods, researchers can determine what conditions produce the most accurate affective forecasts (Wilson \& Gilbert, 2005). A hyperrational approach to these forecasts_-making a mental or physical list of “pros” and “cons,” for instance_-actually compounds the chances of errant conclusions, as prospecting about the effects of each subitem is another opportunity for error (Gilbert, Gill, \& Wilson, 2002). Several research programs indicate that promoting rational decision-making strategies reduces effectiveness (Dijksterhuis \& Nordgren, 2006; Gilbert, 2006; Kahneman \& Tversky, 1996; Wilson, 2002; Wilson et al., 1993) and that intuitive decisions produce superior outcomes (e.g., Dijksterhuis \& Smith, 2005; Gilbert, 2006; Iyengar, Wells, \& Schwartz, 2006; Wilson \& Gilbert, 2005).

An experiment performed by Dijksterhuis and van Olden (2006) exemplifies the methods and results common to dual-processing studies. Based on unconscious thought theory, the researchers were investigating how three types of predecisional deliberation (immediate choice, conscious thought, and unconscious thought) affect choice satisfaction. All participants viewed five different artistic posters one at a time for $15 \mathrm{~s}$ each. After viewing, participants were assigned to one of three conditions. Those in the immediate decision condition were shown all options simultaneously and selected the poster they liked best. Those in the conscious thought condition reviewed each poster individually and listed reasons why they liked and disliked each poster before being shown all options simultaneously, and selecting the one they liked best. Those in the unconscious thought condition were precluded from "thinking through" their choice after viewing the posters by completing an anagram task for $450 \mathrm{~s}$; after which they were presented all options simultaneously and selected the poster they liked best. All participants, 
regardless of condition, then rated their attitude toward the posters using a unipolar, unnumbered 50-point visual analog scale. Three to 5 weeks later, participants were again contacted and asked about their satisfaction with the poster and the monetary value they placed on it. Results showed that those in the unconscious thought condition were significantly more satisfied and placed a higher value on the poster than either of the other conditions.

The methodology employed in the present study is the same basic paradigm used by Dijksterhuis and van Olden (2006). Procedures and materials were modified to emphasize variables related to vocational assessment. Most importantly, participants were asked to forecast feelings of interest instead of satisfaction. The assessment and prediction of interests is vital to the field of vocational psychology, and many of the most commonly used instruments in the field, such as the Strong Interest Inventory (Donnay \& Borgen, 1996) and the Self-Directed Search (Holland, 1978), rely on such forecasts. Although there is no precedent in the literature for this specific form of affective prediction, there is no reason to believe that interest forecasts would function any differently than other well-studied affective forecasting (e.g., Dijksterhuis \& van Olden, 2006, p. 20; Wilson et al., 1993; Wilson \& Schooler, 1991). Interest forecasting represents the merger between the practical realm of career counseling (interests) and the experimental realm of dual-processing theory (affective forecasting).

The following experiment was designed to examine how a history of occupational engagement and predecisional strategy (conscious-rational, unconscious-intuitive, or control) affect how interest-relevant experiences are predicted and remembered. It is expected that a history of occupational engagement will be related to accurate interest forecasts and that unconscious-intuitive decisions will produce superior interest forecasts. 


\section{Method}

\section{Participants and Design}

Participants included 136 students, 52 (38\%) women and 84 (62\%) men, from a large Midwestern university. Mean age of the sample was 21.5 (SD $1 / 44.6$ ), and 67\% identified as White, $11 \%$ as Black, $7 \%$ as Asian, $7 \%$ as multiracial, $4 \%$ as Hispanic, and $4 \%$ as another ethnicity. All participants were offered a 10-dollar incentive and recruited from introductorylevel courses that meet general education requirements. As such, the sample consisted of students with a variety of academic backgrounds: 52 different majors; 28\% were first-year students, 29\% were sophomores, 20\% were juniors, 16\% were seniors, and 7\% had exceeded 4 years of undergraduate education. Participants were randomly assigned to one of three conditions: a control condition, an unconscious-intuitive condition, or a conscious-rational condition. The conditions differed in predecisional strategy manipulation. All participants completed measures, selected one of eight video options, watched the video they chose, and rated their interest.

\section{Measures and Materials}

Occupational Engagement Scale-Student (OES-S). The OES-S is a 9-item instrument validated by Cox, Krieshok, Bjornsen, and Zumbo (2015) as a measure of college student occupational engagement. Engagement is a theoretical extension of the trilateral model of adaptive career decision-making (Krieshok et al., 2009) and measures previous work world-related behavior. The measure has been shown to be reliable $(\alpha=.85)$ and has been found to be a valid measure of occupational engagement in college populations (Cox et al., 2015). Internal consistency of the OES-S in the current sample ( $\alpha=.82)$ suggests sufficient reliability. 
Table I. Standardized Descriptions of the Eight Video Options.

\begin{tabular}{|c|c|c|c|c|c|}
\hline \multirow[b]{2}{*}{ Video } & \multicolumn{5}{|c|}{ Standardized Descriptions } \\
\hline & Field & General Action & Specific Action & Object & Goal \\
\hline$A$ & Medicine & Researching cancer & $\begin{array}{l}\text { Experimenting on } \\
\text { tissue }\end{array}$ & $\begin{array}{l}\text { Human } \\
\text { anatomy }\end{array}$ & Healing illness \\
\hline B & Politics & $\begin{array}{l}\text { Studying economic } \\
\text { power }\end{array}$ & $\begin{array}{l}\text { Examining } \\
\text { government } \\
\text { regulations }\end{array}$ & $\begin{array}{l}\text { Foreign } \\
\text { policy }\end{array}$ & $\begin{array}{l}\text { Promoting international } \\
\text { cooperation }\end{array}$ \\
\hline C & Teaching & $\begin{array}{l}\text { Reforming } \\
\text { education } \\
\text { systems }\end{array}$ & $\begin{array}{l}\text { Interacting with } \\
\text { children }\end{array}$ & Creativity & $\begin{array}{l}\text { Developing children's } \\
\text { talents }\end{array}$ \\
\hline D & Marketing & $\begin{array}{l}\text { Designing } \\
\text { advertising } \\
\text { campaigns }\end{array}$ & $\begin{array}{l}\text { Persuading } \\
\text { customers }\end{array}$ & $\begin{array}{l}\text { Consumer } \\
\text { habits }\end{array}$ & Selling products \\
\hline$E$ & Sculpting & Creating art & $\begin{array}{l}\text { Crafting with one's } \\
\text { hands }\end{array}$ & $\begin{array}{l}\text { Visual } \\
\text { perception }\end{array}$ & $\begin{array}{l}\text { Creating beautiful } \\
\text { works }\end{array}$ \\
\hline $\mathrm{F}$ & Astronomy & Analyzes starlight & $\begin{array}{l}\text { Interpreting scientific } \\
\text { data }\end{array}$ & $\begin{array}{l}\text { Chemical } \\
\text { elements }\end{array}$ & $\begin{array}{l}\text { Searching for alien } \\
\text { planets }\end{array}$ \\
\hline G & Technology & $\begin{array}{l}\text { History of artificial } \\
\text { intelligence }\end{array}$ & $\begin{array}{l}\text { Examining early } \\
\text { software programs }\end{array}$ & Computers & $\begin{array}{c}\text { Creating faster } \\
\text { information } \\
\text { processors }\end{array}$ \\
\hline $\mathrm{H}$ & $\begin{array}{l}\text { Animal } \\
\text { communication }\end{array}$ & $\begin{array}{l}\text { Researching animal } \\
\text { groups }\end{array}$ & $\begin{array}{c}\text { Human-animal } \\
\text { interaction }\end{array}$ & Great Apes & $\begin{array}{l}\text { Learning about animal } \\
\text { abilities }\end{array}$ \\
\hline
\end{tabular}

Video options. Eight occupational/educational videos served as the stimuli in the experiment. Videos were 16- to 18-min lectures selected from the Technology, Entertainment, and Design Conference series (known as “TED talks”), in which an expert or researcher discusses their respective field. Video options were chosen based on focus group feedback and intended to represent a variety of distinct topics that would be of interest to undergraduate students. Each video was summarized with a set of five different standardized descriptions. To ensure the descriptions were equal in information quality and quantity across video options, they were standardized based on (a) the occupational field of the expert, (b) the general occupation-relevant action discussed in the presentation, (c) the specific occupation-relevant action discussed in the presentation, (d) the object studied by the expert, and (e) the goal or purpose of the expert's inquiry. See Table 1 for these descriptions. 
Since there was no way to standardize the videos themselves, they varied somewhat in characteristics unrelated to the content of the lecture, such as production value and lecture features (e.g., use of humor, demonstrations). As such, participant appraisals of the video reflect their reaction to both the topic of the video-which were the basis of the participant prediction and the focus of this study—and these peripheral video characteristics, which also influenced participant interest levels. To account for such differences, during-video interest levels from all participants who chose a particular video were averaged to obtain a general "video quality" metric for each video option. Video quality scores ranged from 38.33 to 46.60 , and this variable was used as a covariate in an attempt to nullify potentially confounding video attributes.

Measuring interest. Interest was assessed using an unnumbered unipolar visual analog scale with each end labeled "not at all interested" and "very interested." Interest items were scored with a standardized template to quantify the participant's response from 0 (not at all interested) to 50 (very interested). This measure was used with success by Dijksterhuis and van Olden (2006), who adopted this measurement style due to its sensitivity to subtle nonconscious affective changes.

Mood assessment. Participant mood was assessed using a single item designed to be congruent with other measures in the study: a 50-point unipolar visual analog scale. Single-item visual analog scales have been found to be valid measures of mood (Williams, Morlock, \& Feltner, 2010). Hirt, Melton, McDonald, and Harackiewicz (1996) found that pretask mood was a significant predictor of interest both before and after participants engaged in a variety of experimental tasks. The inclusion of this item allowed for the control of mood effects that might obscure results. 


\section{Procedure}

The procedure was modeled largely after the previously described experiment by Dijksterhuis and van Olden (2006). Participants completed the study in groups of between four and seven participants at a time. All participants, regardless of condition, completed the OES-S, current mood assessment, and a short demographic questionnaire. Each participant completed a predecisional manipulation before selecting one of the eight video options. Predecisional manipulations, which are described below, differed between experimental conditions. Before watching the video, they were asked to predict how interested they would be while watching the video. They watched the video and rated their interest in it 3 times throughout: after 5 min of video, after 10 min of video, and immediately following the video. These three measurements were averaged to get a single “during-video interest” metric. Participants were contacted two weeks later and asked to rate how interested they felt during the video.

Experimental manipulation. Participants were randomly assigned to one of three conditions: control $(n=44)$, conscious-rational $(n=44)$, or unconscious-intuitive $(n=48)$. Sample sizes are equivalent or greater than those in similar studies (e.g., Dijksterhuis \& van Olden, 2006; Wilson et al., 1993; Wilson \& Schooler, 1991).

Control condition. Participants in the control condition were presented all video descriptions simultaneously and in an organized fashion (using the data in Table 1). They selected the video they believed they would find most interesting. They watched the video they selected and rated their interest levels 3 times throughout.

Conscious-rational condition. Participants in the conscious-rational conditionwere asked to rate each of the 40 video descriptions using a 9-point Likert-type scale. They then tallied each 
video total, yielding a single interest score for each video. Pilot testing showed that participants needed approximately 5 min to complete the description ratings. Participants were presented all video descriptions simultaneously and in an organized fashion and asked to select the video that would be most interesting. Though they were free to choose any video, a review of participant protocols found that all participants in this condition selected the video that they rated as most interesting using the Likert-type scales. This method was intended to induce a hyperrational, reductionistic decision-making strategy and simulate the methods and instruments that are very common in career counseling. Participants in the conscious-rational condition then watched the video they chose and rated their interest levels 3 times throughout.

Unconscious-intuitive condition. Before being asked to choose between videos, participants in this group were presented the descriptions of the videos via computer program. For instance, one description read as follows: “VIDEO A: Medicine.” Each of the 40 descriptions was flashed on the screen for $3 \mathrm{~s}$ at a time. This process was repeated, so that participants watched the presentation for a total of $4 \frac{1}{2} \mathrm{~min}$, seeing each video description for $3 \mathrm{~s}$ twice. Participants were given instructions not to attempt to memorize these descriptions but to "remain attentive and attempt to absorb the information.” After this, they were given a 5-min distracter task consisting of solving anagrams. Anagram words were selected from the

Table 2. Bivariate Correlation Matrix for Variables of Interest, All Participants.

\begin{tabular}{|c|c|c|c|c|c|}
\hline Variable & 1 & 2 & 3 & 4 & 5 \\
\hline I. Pre-video interest & - & & & & \\
\hline 2. During-video interest & $.36 * *$ & - & & & \\
\hline 3. Follow-up interest & $.45^{* *}$ & $.87 * *$ & - & & \\
\hline 4. OES-S & $.27 * *$ & $.25 * *$ & $.24 *$ & - & \\
\hline 5. Mood & $.38 * *$ & $.36 * *$ & $.32 * *$ & $.20 *$ & - \\
\hline 6. Video quality & -.004 & $.34 * *$ & $.31 * *$ & .14 & -.04 \\
\hline
\end{tabular}

Note. $N=129$.

$* p<.05$. $* * p<.01$. 
emotionally neutral words cataloged in the affective norms for English words (word list (Bradley \& Lang, 1999). This anagram distracter task was intended to allow for unconscious thought and the development of affective, gist-level appraisals of the options. Participants were presented all video descriptions simultaneously and in an organized fashion and asked to select the video that would be most interesting. They then watched the video they chose and rated their interest levels 3 times throughout.

Follow-up. Approximately 2 weeks following the initial data collection, participants were asked to reread the descriptions of the videos and rate how interested they remembered feeling during the video. Interest levels at follow-up were assessed using the same unnumbered visual analog scale. Of the 136 initial participants, 115 (85\%) completed the follow-up survey.

\section{Results}

An initial screening of the data revealed that during-video and follow-up interest variables were found to have a significant negative skew. Gamst, Meyers, and Guarino (2008) recommend eliminating outliers with $z$-scores greater than \pm 2.5 in order to normalize data prior to analysis. Four participants (one from the control group, one from the conscious-rational group, and two from the unconscious-intuitive group) were found to have $z$-scores greater than \pm 3 .0. These four scores were considerably more extreme than other cases in the data set; as the next most extreme score had a $z$-score of -1.78 . Plots and descriptive statistics suggested that, following the elimination of these cases, the data distributions were sufficiently normally distributed for all outcome variables. Two participants omitted important variables, and another did not follow directions during the experiment. A total of 129 usable participant cases remained for analysis. 
One-way analyses of variance found age, college grade point average, number of college credits, OES-S score, and mood did not differ among groups, and a $\chi^{2}$ test for goodness of fit indicated that the video options were chosen at the same rate across experimental groups. Together, these results suggest random assignment was successful, and experimental condition did not affect mood.

A correlation matrix of the primary variables examined in this study is presented in Table 2. Similar to the findings of Hirt et al. (1996), participant mood was found to be significantly related to during-video interest appraisals, $r(127)=.36, p<.001$. Video quality was also found to be related to during-video interest appraisals, $r(127)=.34, p<.001$. In addition, a one-way analysis of variance found that there were significant differences across video quality scores, $F(7,121)=2.22, p=.037, \eta^{2}=.11$. These two variables—both extraneous to the research questions—exerted considerable influence on the dependent variables in the study. As such, they were statistically controlled for in the following analyses.

Table 3. Partial Correlations, Controlling for the Effects of Mood and Video Quality.

\begin{tabular}{|c|c|c|c|c|c|c|c|c|c|c|c|c|}
\hline \multirow[b]{2}{*}{ Partial Correlations } & \multicolumn{3}{|c|}{$\begin{array}{l}\text { All Participants } \\
\qquad(N=129)\end{array}$} & \multicolumn{3}{|c|}{$\begin{array}{l}\text { Control } \\
\text { Condition } \\
(n=4 I)\end{array}$} & \multicolumn{3}{|c|}{$\begin{array}{l}\text { Conscious- } \\
\text { Rational Condition } \\
\quad(n=43)\end{array}$} & \multicolumn{3}{|c|}{$\begin{array}{l}\text { Unconscious- } \\
\text { Intuitive Condition } \\
\quad(n=45)\end{array}$} \\
\hline & $\mathrm{TI}$ & T2 & $\mathrm{T} 3$ & TI & $\mathrm{T} 2$ & T3 & $\mathrm{TI}$ & $\mathrm{T} 2$ & T3 & TI & $\mathrm{T} 2$ & $\mathrm{~T} 3$ \\
\hline Pre-video interest (TI) & - & & & - & & & - & & & - & & \\
\hline During-video interest (T2) & $.29 * *$ & - & & .22 & - & & .17 & - & & $.53 * *$ & - & \\
\hline Follow-up interest (T3) & $.41^{* *}$ & $.85^{* *}$ & - & $.45^{* *}$ & $.86 *$ & - & .32 & $.89 * *$ & - & $.52 * *$ & $.81^{* *}$ & - \\
\hline OES-S & $.2 I^{*}$ & $.23 *$ & $.22 *$ & .10 & $.39 *$ & $.43 *$ & $.39 *$ & .17 & .25 & .22 & .21 & .01 \\
\hline
\end{tabular}

Note. OES-S = Occupational Engagement Scale-Student.

$*_{p}<.05 . * * p<.01$.

\section{Engagement and Interest}

Partial correlations controlling for participant mood and video quality were performed to explore the relation between during-video interest and engagement. Using the entire sample, partial 
correlations between OES-S scores and during-video interest levels were significant, $r(125)=$ $.23, p=.011$. Further analysis, however, indicated that while these variables correlated in the predicted direction for all three conditions, that relation was significant only in the control group, $r(37)=.39, p=.013$, and not in the conscious-rational group, $r(39)=.17, p=.292$, or the unconscious-intuitive group, $r(41)=.21, p=.181$ (Table 3).

\section{Interest Forecast Accuracy}

During-video interest levels were analyzed across conditions using an analysis of covariance controlling for participant mood and video quality. A main effect for treatment condition was not found, $F(2,130)=1.40, p=.23$. In addition, a partial correlation controlling for the effects of participant mood and video quality revealed a significant and positive relationship, $r(124)=.29$, $p=.001$, between prevideo interest and during-video interest in the sample overall. When treatment groups were analyzed independently, however, only the unconscious-intuitive group displayed a significant relationship between prevideo and during-video interest ratings, $r(40)=$ $.53, p=.001$; whereas the control, $r(37)=.22, p=.176$, and conscious-rational, $r(39)=.17, p=$ .303 , conditions did not.

\section{Interest Levels Over Time}

Interest levels were examined across the 3 times: before the video (Time 1), an average of three interest assessments made during the video (Time 2), and 2 weeks following the video (Time 3). Raw mean interest scores were adjusted to control for mood, video quality, and OES-S scores. OESS scores were included as a covariate due to the significant correlation between engagement and interest levels unevenly distributed across groups. A $3 \times 3$ (group $\times$ time) repeated-measures analysis of covariance was conducted on the data, which required Greenhouse-Geisser-corrected 


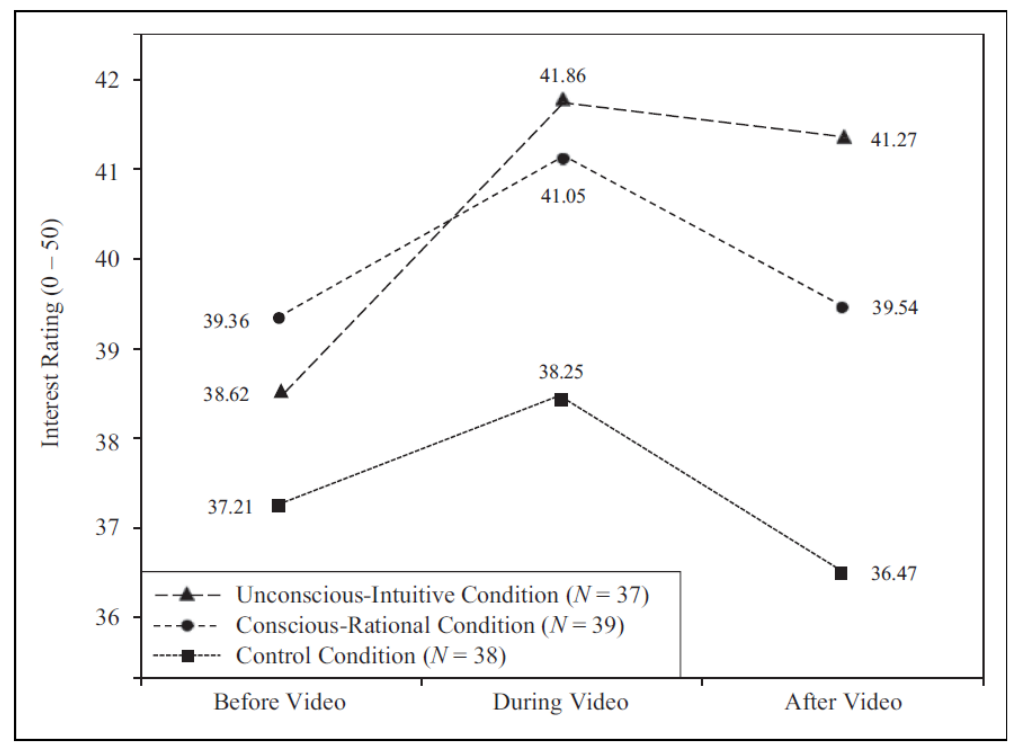

Figure I. Group mean interest scores over time after adjusting for participant mood, Occupational Engagement Scale-Student scores, and video quality.

degrees of freedom to compensate for a violation of the assumption of sphericity. A significant interaction between group and time did not appear, $F(2.46,133.98)=.62, p=.75$; nor did a main effect for group, $F(2,108)=1.70, p=.31$. Finally, a significant main effect emerged for time,

$F(1.23,130.43)=8.51, p=.002$, partial $\eta^{2}=.13$. Post hoc analyses using a Bonferroni correction revealed that the overall sample displayed a distinct "inverted V" pattern across time: There was a significant increase in mean interest scores from Time $1(M=38.4, S D=4.35)$ to Time $2(M=$ 40.39, $S D=4.93), p=.03$; and a significant decrease from Time 2 to Time $3(M=39.10, S D=$ 5.38), $p=.001$. The difference between Time 1 and Time 3 was not significant, $p=1.00$.

Additional analyses of covariance controlling for mood, video quality, and OES-S were conducted for each group to further examine the significant main effect for time. All follow-up tests also used Bonferroni corrections to control for alpha inflation. The control group $(N=38)$ displayed the same pattern as the overall sample: a main effect for time, $F(1.27,43.05)=4.70, p$ $=.03$, partial $\eta^{2}=.12$, with a significant decline in interest levels from Time $2(M=38.25, S D=$ 
$10.07)$ to Time $3(M=36.47, S D=10.52), p=.02$; but no difference between Time $1(M=$ $37.21, S D=8.43)$ and Time $3, p=1.00$. The conscious-rational group $(N=39)$ displayed the same pattern: a main effect for time, $F(1.22,42.69)=3.52, p=.04$, partial $\eta^{2}=.09$, with a significant decline in interest levels from Time $2(M=41.05, S D=6.85)$ to those at Time $3(M=$ 39.54, $S D=8.69), p=.01$; but no difference between Time $1(M=39.36, S D=5.68)$ and Time $3, p=1.00$.

Using the same statistical procedure, the unconscious-intuitive group $(N=37)$ did not display a main effect for time, $F(1.22,40.31)=1.77$, $n s$, and unlike the control and consciousrational groups, there was no significant decline between Time $2(M=41.86, S D=7.96)$ and Time $3(M=41.27, S D=8.63), n s$. Also, the difference between Time $1(M=38.62, S D=8.45)$ and Time $3(M=41.27, S D=8.65)$ was greater than in either of the other two groups, and the increase approached significance, $p=.09$. See Figure 1 for a graphic representation of the pattern of interest scores over time for the three conditions.

\section{Discussion}

The methods in this study were designed to foster three different decisional strategies. Those in the control condition had no structure or motivation to adopt any specific deliberative strategy. Those in the conscious-rational decision were prompted to adopt a reductionistic, hyperrational, and quantitative decisional strategy that is similar to that required by many current vocational interest assessments. Those in the unconscious-intuitive condition were immersed in decision-relevant stimuli but were precluded from conscious deliberation by way of a distractor task. 
OES-S scores were positively correlated with reported interest levels during the video. These results offer general support for the idea that occupational engagement, as measured by the OES-S, is related to better interest forecasting as measured by during-video interest in participant video of choice. However, after controlling for potentially confounding variables (i.e., participant mood and video quality), the association was only significant for the control group.

Though it is possible that a trait propensity to find activities interesting is responsible for this relationship, this explanation would not account for the differential effects across the conditions. If high occupational engagement scores represent a latent personality variable, such as extroversion, it would be expected that the relationship would be observed across all groups.

The relation between the two variables most likely represents, as operationalized, an association between past engagement behaviors and ability to forecast interests under usual conditions. When participants were left to their own devices, a history of occupational engagement displayed a positive relationship of moderate strength with the accuracy of interest forecasts.

These results offer tentative support for the contention that engagement is beneficial in immediate, “decision-as-usual” situations; those in which typical, idiosyncratic patterns of interaction with decision-relevant stimuli are not interrupted. Under such circumstances, it appears that previous engagement activities may be associated with better occupational or educational decisions. This interpretation also suggests that occupational engagement informs the process used to produce daily interest forecasts, a finding that supports Krieshok et al.’s (2009) definition of the construct and Cox et al.'s (2015) operationalization of it. 
Interest forecast accuracy was measured two ways. First, actual interest levels assessed during the video were used as a metric to determine the extent to which the video that was chosen reflected the "best choice.” Thus, greater interest levels during that video, after specific contextual and characterological factors were controlled, can be interpreted as better predictions. Using this metric, results did not indicate that decisional strategy (control, conscious-rational, or unconscious-intuitive) significantly influenced success of interest forecasts.

A second measure of interest forecast accuracy was calculated by examining the correlations between prevideo predictions and during-video interest scores. The strength of this relationship serves as a metric to determine the degree to which interest forecasts actually predicted future interest levels; accurate forecasts would be expected to correlate strongly and positively to actual interest levels. Only members of the unconscious-intuitive group reported interest forecasts that reliably predicted their actual interest levels. It appears unconsciousintuitive procedures led to forecasts that were more predictive of actual interest than did either of the other strategies.

As a whole, the sample displayed an "inverted V" pattern of interest over time. Participants were surprised by their interest levels during the videos, as they were, on average, more interested during the video than they expected they would be. When asked 2 weeks later, however, they reported an interest level indistinguishable from their prevideo expectation and significantly below that which they reported while watching their video. That is, after 2 weeks, participants in the consciousrational and control groups significantly misremembered their experience. They more closely recalled their expectation of the video than their experience of it. Both the control condition and the conscious-rational condition displayed this pattern. 
Participants in the unconscious-intuitive group were likewise pleasantly surprised by how interested they were during their video, as indicated by a significant increase from prevideo to during-video interest level. Unlike the other two groups, however, follow-up interest scores decreased only slightly from during-video scores. In fact, follow-up interest scores were indistinguishable from during-video scores, and considerably higher than their prevideo scores. In contrast to the other conditions, participants in the unconscious-intuitive condition more closely recalled their experience of the video, than their expectation of it.

One possible interpretation of these findings is that one's predecisional strategy may have effects beyond simply influencing which option is chosen. In this case, the manner in which one contemplated an occupational/educational decision appears to have influenced how accurately one recalled internal states (i.e., interest levels) during that event. It is certain that decision makers in the conscious-rational condition—and likely that those in the control condition— produced conscious, rational, and logical reasons for their interest forecasts. Although this may not necessarily have resulted in significantly poorer choices, it may have significantly altered their recollections of the outcomes of those choices.

When one approaches a choice by activating a logical narrative (i.e., a conscious-rational interest forecast), they create two separate and potentially competing experiences: the act of consciously constructing a forecast and the experience of the event itself. Two weeks later, when the descriptions of the videos were represented and participants were asked for a single evaluation of the memory, the logic behind the prediction was easily recalled, as neither the selfnarratives nor the video descriptions had changed. Logico-verbal rules are generalized, resulting in consistency across situations (e.g., "I am the type of person who would be interested in this"), even if such consistency comes at the cost of accuracy. Those individuals in the unconscious- 
intuitive group would not have had a well-formed rationale to compete with their experience. Instead, the unconscious-intuitive condition created a vague, gist-level, affective response to each option, rather than discrete reasons for selecting an option.

This interpretation of the findings is consistent with several dual-processing theories. For example, Epstein, Pacini, Denes-Raj, and Heier (1996) asserted that "the experiential system operates in a context-specific manner," while "responses influenced by the rational system, which operates according to context-free, abstract principles, should be more cross-situationally consistent” (p. 393). From this perspective, the misremembering displayed by the consciousrational and control groups resulted from an overgeneralization of narrative self-knowledge (e.g., "I am the type of person who would like this"). FTT suggests that information that is processed and gestated at the gist level is more easily and accurately recalled than information processed at a specific, verbatim level. FTT stipulates that gistlevel experiences are more amenable to meaning making than are verbatim data (Reyna \& Brainerd, 1995). In the current study, the unconscious-intuitive group was forced to form gist-level appraisals of the options through the stimulus immersion procedure (exposing participants to the descriptors for $3 \mathrm{~s}$ each) and prevented from conscious, verbatim processing through the anagram distracter task.

\section{Conclusions}

In total, the findings from this study suggest that the manner in which individuals process relevant information preceding a decision, in the form of engagement and decisional strategy, will influence interest forecasts and recollections of interest levels during experiences. Three specific conclusions are worth noting: 
1. A history of engagement behavior was found to be helpful when making decisions without structure (i.e., decisions-as-usual).

2. Though an unconscious-intuitive strategy was not found to produce definitively better choices, it appeared to produce interest forecasts that were more predictive of actual interest than did conscious-rational or control strategies.

3. Conscious-rational and control strategies resulted in recollections of events that were different from what was experienced and similar to what was expected. An unconscious-intuitive strategy resulted in the opposite: recollections that were similar to what was experienced and different from what was expected.

\section{Limitations and Future Directions}

There are limitations to the current study. First, in general, tests of between-group mean differences across experimental conditions, while often significant and in the predicted direction, were not as persuasive as expected. External validity was prioritized; potency and control were sacrificed for ecological legitimacy and generalizability. Replication studies, particularly as they relate to the prediction and memory of interest appraisals, may emphasize experimental control to boost power and potency. Specifically, though methods were designed to induce a particular information processing strategy prior to a decision, there was no manipulation check regarding how participants actually went about deciding among videos. Future studies may circumvent this problem by exerting greater experimental control. Lastly, the outcome of participant's choice was of little consequence, as they were informed the video would only last about 15 min, which certainly mitigated participants' appraisal of interest. A boring video may be considered slightly uninteresting (i.e., a fairly poor choice), but a boring job that consumes $40 \mathrm{hr}$ each week would likely be considered incredibly uninteresting (i.e., a very poor choice). Introducing outcomes of 
greater importance could increase variability among cases, highlighting differences in decisional quality. In general, it is hoped that the theory and methodology introduced here will inspire further exploration of interest appraisals in the light of modern decision-making theory.

\section{Declaration of Conflicting Interests}

The author(s) declared no potential conflicts of interest with respect to the research, authorship, and/or publication of this article.

\section{Funding}

The author(s) received no financial support for the research, authorship, and/or publication of this article. 


\section{References}

Bargh, J. A., \& Chartrand, T. L. (1999). The unbearable automaticity of being. American Psychologist, 54, 462-479. doi:10.1037/002-3514.76.6.893

Bechara, A., Damasio, H., Tranell, D., \& Damasio, A. R. (1997). Deciding advantageously before knowing the advantageous strategy. Science, 275, 1293-1296. doi:10.1126/science.275.5304.1293

Bradley, M. M., \& Lang, P. J. (1999). Affective norms for English words (ANEW): Stimuli, instruction manual and affective ratings (Technical report C-1). Gainesville: The Center for Research in Psychophysiology, University of Florida.

Cox, D. W., Krieshok, T. S., Bjornsen, A. L., \& Zumbo, B. D. (2015). Occupational Engagement Scale-student: Development and initial validation. Journal of Career Assessment, 23, 107-116. doi:10.1177/1069072714523090

Dijksterhuis, A., \& Nordgren, L. F. (2006). A theory of unconscious thought. Perspectives on Psychological Science, 2, 95-109. doi:10.1111/j.1745-6916.2006.00007.x

Dijksterhuis, A., \& Smith, P. K. (2005). What do we do unconsciously? And how? Journal of Consumer Psychology, 15, 225-229. doi:10.1207/s15327663jcp1503_7

Dijksterhuis, A., \& van Olden, Z. (2006). On the benefits of thinking unconsciously: Unconscious thought can increase post-choice satisfaction. Journal of Experimental Social Psychology, 42, 627-631. doi:10.1016/j.jesp.2005.10.008

Donnay, A. C., \& Borgen, F. H. (1996Validity, structure, and content of the 1994 Strong Interest Inventory. Journal of Counseling Psychology, 43, 275-291. doi:10.1037/00220167.43.3.275

Epstein, S. (1994). Integration of the cognitive and the psychodynamic unconscious. American Psychologist, 49, 709-724. doi:10.1037/0003-066X.49.8.709

Epstein, S., Pacini, R., Denes-Raj, V., \& Heier, H. (1996). Individual differences in intuitiveexperiential and analytical-rational thinking styles. Journal of Personality and Social Psychology, 71, 390-405. doi:10.1037/0022-3514.71.2.390 
Evans, B. T. (2008). Dual-processing accounts of reasoning, judgment, and social cognition. Annual Review of Psychology, 59, 255-278. doi:10.1146/annurev.psych.59.103006.093629

Gamst, G., Meyers, L. S., \& Guarino, A. J. (2008). Analysis of variance designs: A conceptual and computational approach with SPSS and SAS. New York, NY: Cambridge.

Gilbert, D. T. (2006). Stumbling on happiness. New York, NY: Alfred A. Knopf.

Gilbert, D. T., Gill, M. J., \& Wilson, T. D. (2002). The future is now: Temporal correction in affective forecasting. Organizational Behavior and Human Decision Processes, 88, 430444. doi:10.1006/obhd.2001.2982

Greenwald, A. G., \& Farnham, S. D. (2000). Using the implicit association test to measure selfesteem and selfconcept. Journal of Personality and Social Psychology, 79, 1022-1038. doi:10.1037//0022-3514.79.6.I022

Greenwald, A. G., McGhee, D. E., \& Schwartz, J. L. K. (1998). Measuring individual differences in implicit cognition: The implicit association test. Journal of Personality and Social Psychology, 74, 1464-1480. doi:10.1037/0022-3514.74.6.1464

Hirt, E. R., Melton, R. J., McDonald, H. E., \& Harackiewicz, J. M. (1996). Processing goals, task interest, and the mood-performance relationship: A mediational analysis. Journal of Personality and Social Psychology, 71, 245-261. doi:10.1037//0022-3514.71.2.245

Holland, J. L. (1978). Manual for the vocational preference inventory. Palo Alto, CA: Consulting Psychologists Press.

Holland, J. L., Sorensen, A. B., Clark, J. P., Nafziger, D. H., \& Blum, Z. D. (1973). Applying an occupational classification to a representative sample of work histories. Journal of Applied Psychology, 58, 34-41. doi:10.1037/h0035405

Iyengar, S. S., Wells, R. E., \& Schwartz, B. (2006). Doing better but feeling worse: Looking for the "best" job undermines satisfaction. Psychological Science, 17, 143-150. doi:10.1111/j.1467-9280.2006.01677.x 
James, R. K., \& Gilliland, B. E. (2003). Trait-factor counseling/person x environment fit [Supplemental material]. In R. K. James \& B. E. Gilliland (Eds.), Theories and strategies in counseling and psychotherapy (5th ed.). Boston, MA: Allyn \& Bacon. Retrieved from http://wps.ablongman.com/wps/media/objects/208/213944/trait.pdf

Janis, I., \& Mann, L. (1977). Decision making: A psychological analysis of conflict, choice, and commitment. New York, NY: Free Press.

Kahneman, D., \& Tversky, A. (1996). On the reality of cognitive illusions. Psychological Review, 103, 582-591. doi:10.1037/0033-295X.103.3.582

Klein, G. A. (2003). The power of intuition: How to use your feelings to make better decisions at work. New York, NY: Random House.

Krieshok, T. S. (1998). An anti-introspectivist view of career decision-making. The Career Development Quarterly, 46, 210-228.

Krieshok, T. S. (2001). How the decision-making literature might inform career center practice. Journal of Career Development, 27, 207-216. doi:10.1023/A:1007839110404

Krieshok, T. S., Black, M. D., \& McKay, R. A. (2009). Career decision-making: The limits of rationality and the abundance of non-conscious processes. Journal of Vocational Behavior, 75, 275-290. doi:10.1016/j.jvb.2009.04.006

Krumboltz, J. D. (2009). The happenstance learning theory. Journal of Career Assessment, 17, 135-154. doi:10.1177/1069072708328861

Levine, G. M., Halberstadt, J. B., \& Goldstone, R. L. (1996). Reasoning and the weighting of attributes in attitude judgments. Journal of Personality and Social Psychology, 70, 230240. doi:10.1037/0022-3514.70.2.230

Melchior, L. A., \& Cheek, J. M. (1990). Shyness and anxious self-preoccupation during a social interaction. Journal of Social Behavior \& Personality, 5, 117-130.

Miller, G. A. (1956). The magical number seven, plus or minus two: Some limits on our capacity for processing information. Psychological Review, 63, 81-97. doi:10.1037/h0043158

Parsons, F. (1909). Choosing a vocation. Boston, MA: Houghton Mifflin. 
Reyna, V. F., \& Brainerd, C. J. (1995). Fuzzy-trace theory: Some foundational issues. Learning and Individual Differences, 7, 145-162. doi:10.1016/1041-6080(95)90028-4

Super, D. E. (1980). A life-span, life-space approach to career development. Journal of Vocational Behavior, 16, 282-298.

Williams, V. S. L.,Morlock, R. J., \& Feltner, D. (2010). Psychometric evaluation of a visual analog scale for the assessment of anxiety. Health and Quality of Life Outcomes, 8, 1-8. doi:10.1186/1477-7525-8-57

Wilson, T. D. (2002). Strangers to ourselves: Discovering the adaptive unconscious. Cambridge, MA: Harvard.

Wilson, T. D., \& Gilbert, D. T. (2005). Affective forecasting: Knowing what to want. Current Directions in Psychological Science, 14, 131-134. doi:10.1111/j.09637214.2005.00355.x

Wilson, T. D., Lisle, D. J., Schooler, J. W., Hodges, S. D., Klaaren, K. J., \& LaFleur, S. J. (1993). Introspecting about reasons can reduce post choice satisfaction. Personality and Social Psychology Bulletin, 19, 331-339. doi:10.1177/0146167293193010

Wilson, T. D., \& Schooler, J. W. (1991). Thinking too much: Introspection can reduce the quality of preferences and decisions. Journal of Personality and Social Psychology, 60, 181-192. doi:10.1037/0022-3514.60.2.181 